\title{
Developing Humanistic Competencies Within the Competency-Based Curriculum
}

\author{
Satendra Singh, Upreet Dhaliwal and NaVJeevan Singh \\ From the Health Humanities Group, University College of Medical Sciences (University of Delhi) and GTB Hospital, Delhi, India. \\ Correspondence to: Dr Satendra Singh, Department of Physiology, University College of Medical Sciences, Delhi 110 095, India. \\ dr.satendra@gmail.com
}

We herein, describe the rationale, content, methodology and evaluation of a health humanities module in the new competency-based curriculum, and share our experience of the same. Providing training in health humanities to the healthcare trainees will definitely go a long way in having a professional and responsive Indian medical graduate, who is able to provide empathetic and holistic healthcare to all sections of the society.

Keywords: Cultural diversity, Disability studies, Medicine in the Arts, Narrative medicine, Patient advocacy, Professionalism.

Published online: September 5, 2020; PII: S097475591600236

$\mathrm{T}$ he humanities being incorporated in medical education is a relatively newer concept in our country. There are various reasons that prompted the authorities to consider using the humanities in medical teaching: student burnout, mental health issues, and suicides; faculty and provider burnout; student anecdotes about faculty teaching by humiliation; provider-patient encounters resulting in miscommunication; missing empathy and poor communication skills; violence perpetrated by patients' relatives; and public displays by providers showing unprofessionalism and unethical behavior [1-4]. Clearly, conventional medical education methods were lacking a critical humanitarian element [5]. These observations confirm the intuitive rationale for the inclusion of the humanities in health professions education (HPE) - "to educate for sensitivity so that we do not produce [providers] who place cases and smart diagnoses before persons and feelings" [6].

\section{THE EVOLUTION OF MEDICAL HUMANITIES}

The Flexner report revolutionized medical education in the US in 1910, but 15 years later, Abraham Flexner was appalled that students had no grounding in the humanities before they arrived for medical training [6]. Historian George Sarton coined the term 'medical humanities' in the US in 1947. The first department of humanities was established in 1967 at Pennsylvania State University's College of Medicine, and the first Institute for the Medical Humanities at the University of Texas Medical branch in Galveston a few years later [6]. The UK joined the movement by organising the first UK medical humanities conference in 1998 [6].
In India, University College of Medical Sciences was the first medical college to document introduction of humanities to medical students, faculty and non-teaching staff through the creation of a Medical Humanities Group (now called Health Humanities Group) in the year 2009. Other Indian institutions that followed this lead in the initial years were Jorhat Medical College, Assam; Seth GS Medical College, Mumbai; and St John's Research Institute, Bangalore. The medical humanities movement also received exposure because of journals that dedicated themselves to the cause. It started with the Journal of Medical Humanities in the US in 1979. Research and Humanities in Medical Education (RHiME), an open access peer-reviewed online-only journal, the only medical humanities journal in Asia, was started in 2014. Interestingly, the journal also encourages submissions in Indian vernacular languages, particularly Hindi.

\section{Medical Humanities or Health Humanities}

This topic has generated a great deal of debate. While it all began as the medical humanities, some feel that adding the 'medical' to the humanities creates an unfortunate and restrictive association that compels one to examine the humanities from the perspective of medicine and not in their own right [5]. Others find that the term seems to preclude 'health', which has a broader reach than that of medicine. In their view, in a kind of tubular vision, this term focuses on the patient-provider relationship, while 'health' as a construct includes the socio-cultural aspects and historical biases of the cultures [7]. Additionally, the term 'medical' seems to exclude other providers of healthcare, like nurses, pharmacists, and technicians, and 
the receivers of healthcare, like the patients and their caregivers. This differentiation between the two, and the debate around whether they are completely diverse or if one (health humanities) should replace the other (medical humanities), is a continuing debate [7]. When we began our experimentations with the humanities, we envisaged our medical humanities practice as being inclusive of cultural diversity, of disability, of social justice, and of everything - medical or artistic or humanities-based that could benefit the provider-patient-caregiver circle in the long run [4]. For that reason, we find the distinction to be a matter of semantics and we embrace the term Health Humanities in deference to all "healthcare providers, patients and family caregivers" [8]. The special interest group under the aegis of Academy of Health Professions Educators is also named Health Humanities [9].

\section{HUMANISTIC COMPETENCIES}

"Medicine is the most humane of sciences, the most empiric of arts, and the most scientific of humanities"-

Edmund Pellegrino

Around a decade back, we developed experiential workshops that employed different tools from the humanities. The workshops, designed to engage faculty and students from other medical institutions in the humanities, led us to develop an integrated, interdisciplinary humanities approach to the development of appropriate analytical Attitude, ethical and professional Behaviour, effective Communication, respect for Diversity, and Empathy (the ABCDE paradigm) [4,10-12].
We, herein, broaden the theoretical framework of Peterkin [13] and apply it to the ABCDE attributes [4] these, then, directly translate into five competencies that we believe all health professions learners should seek to acquire. These five 'humanistic competencies' are narrative competence, critical reflexivity, visual literacy, advocacy, and structural humility. In India, of all health professions educators (HPE) regulatory bodies, only the Medical Council of India (MCI) has updated the medical curriculum and has aligned it to a competency-based system [14]; therefore, we use that to exemplify how the five humanistic competencies are complementary to the five roles of an Indian Medical Graduate (IMG) as prescribed by the MCI (Table I). At the time of writing, the Nursing Council of India (NCI) has also uploaded a draft document [15], and we also refer to the draft competencies from that document. This may serve the purpose for other health professions' educators who wish to include humanistic competencies in their own curricula.

\section{Narrative Competence}

The first expected role of an IMG is to be a clinician who compassionately promotes health, and prevents, cures, and manages illness in a holistic way [14]. Clinicians must consider the patient as a whole; likewise, they must engage with their patients with more than just their intellects, involving also their hearts and their emotions in the interactions. Such engagement can happen only when clinicians are able to absorb, interpret and respond to the patient-provider stories unfolding in front of them. The

Table I Suggested Tools to Develop Humanistic Competencies

\begin{tabular}{|c|c|c|c|c|}
\hline Roles of IMG ${ }^{*}$ & $\begin{array}{l}\text { Nursing } \\
\text { competencies }^{\#}\end{array}$ & $\begin{array}{l}A B C D E \\
\text { paradigm }\end{array}$ & $\begin{array}{l}\text { Humanistic } \\
\text { competency }\end{array}$ & Suggested tools \\
\hline Clinician & $\begin{array}{l}\text { Patient-centered care; } \\
\text { Evidence-based } \\
\text { practice; Safety }\end{array}$ & $\begin{array}{l}\text { Analytical } \\
\text { attitude }\end{array}$ & $\begin{array}{l}\text { Narrative } \\
\text { competence }\end{array}$ & $\begin{array}{l}\text { Stories, Narrative medicine (illness narratives, life } \\
\text { writings, metaphors, close reading, connotation, } \\
\text { denotation), Medical history, Poetry, Literature, } \\
\text { Theology, Philosophy }\end{array}$ \\
\hline Professional & Professionalism & $\begin{array}{l}\text { Professional } \\
\text { behavior }\end{array}$ & $\begin{array}{l}\text { Critical } \\
\text { reflexivity }\end{array}$ & $\begin{array}{l}\text { Bioethics, Theatre of the Oppressed, Reflections, } \\
\text { Critical thinking, Professional identity formation }\end{array}$ \\
\hline Communicator & Communication & $\begin{array}{l}\text { Effective } \\
\text { communication }\end{array}$ & $\begin{array}{l}\text { Visual } \\
\text { literacy }\end{array}$ & $\begin{array}{l}\text { Visual arts, Reading films, Graphic medicine } \\
\text { (Comics), Image theatre, Performance (Street theatre), } \\
\text { Creative writing }\end{array}$ \\
\hline Leader & $\begin{array}{l}\text { Leadership; System- } \\
\text { based practice; Teamwork } \\
\text { and collaboration }\end{array}$ & $\begin{array}{l}\text { Respect for } \\
\text { diversity }\end{array}$ & Advocacy & $\begin{array}{l}\text { Mentoring, Postmodernism, Social Justice studies } \\
\text { (disability studies, feminism, gender studies, age } \\
\text { studies, dalit rights) }\end{array}$ \\
\hline $\begin{array}{l}\text { Lifelong } \\
\text { learner }\end{array}$ & $\begin{array}{l}\text { Health informatics and } \\
\text { technology; Quality } \\
\text { improvement }\end{array}$ & Empathy & $\begin{array}{l}\text { Structural } \\
\text { humility }\end{array}$ & $\begin{array}{l}\text { Forum theatre, Patients as educators, Identity, } \\
\text { Wellness, Music, Dance, Digital humanities }\end{array}$ \\
\hline
\end{tabular}

IMG-Indian Medical Graduate; *As per Medical Council of India [14]; ${ }^{*}$ As per Indian Nursing Council [15]; ABCDE: Attitude, behavior, communication, diversity and empathy [4]. 
analytical attitude required to witness the patient's story has been termed as narrative competence, which enables a clinician to practice medicine with empathy, reflection, professionalism, and trustworthiness [16].

\section{Critical Reflexivity}

The MCI expects an IMG to be a professional, one who demonstrates a commitment to the profession, who ethically responds to patient needs, and is accountable to them and to the community [14]. The patient-physician relationship in India is still largely paternalistic. This attitude, unfortunately on display in the 'hidden' curriculum, impacts future learners.

Critical reflexivity refers to the understanding of one's own limitations and of the social realities (beliefs, values, social structures) of others [17]. Through it one can examine the assumptions underlying clinical practice and understand how such dimensions influence professional behavior. This competency is inherently creative and we have extensively used Augusto Boal's theatre of the oppressed (TO) to encourage learners to reflect and to understand professionalism [4,10-11].

\section{Visual Literacy}

The next role of an IMG is that of a communicator who has to connect with peers, with patients, their families, and the community [14]. Effective communication involves all of our senses. Visual literacy is the ability to see, to understand and, ultimately, to communicate visually. Visual communication is a process of noticing, not merely the sickness, but the whole person who is often neglected and even hidden from the provider. A visually literate IMG will be able to 'see' the anguished looks and the frowns, the tears and the smiles beyond just the disease.

\section{Advocacy}

The MCI expects an IMG to be a 'Leader' of the healthcare team and a member of the healthcare system [14]. This involves self-awareness of social accountability which is the capacity to respond to society's health disparities and to address such needs through interprofessional collaboration [18]. This necessitates advocacy which is the process of people participating in decision-making processes affecting their own lives, and society in general. An important component of this is giving voice to the most vulnerable. Health humanities is, in essence, a form of advocacy - a means of addressing problems of under-representation as in feminism, disability justice, and transgender rights.

Educators have highlighted how the new CBME curriculum lacks emphasis on respect for diversity [19].
By recognizing the lived experiences of doctors with disabilities and in response to the global disability rights movement's motto of 'Nothing about us, without us, 'we framed disability competencies for health professions education [12]. Going a step further, we were also able to bring about policy change and curricular reform through advocating for its inclusion into the new curriculum [12].

\section{Structural Humility}

The coronavirus pandemic has highlighted an important role of an IMG - that of a 'lifelong learner' who is obligated to improve skills and knowledge over time [14]. The pandemic has taught us to face the fear of managing uncertainties, and to recognize the complexity of the structural constraints that patients and doctors operate under. Structural oppressions within the community and the healthcare system tend to preserve rather than mitigate social inequities and health disparities.

Cultural competency is a term used to signify the identification of our own biases in order to improve patient-provider relationships. It came into existence when it was recognized that physician beliefs were also culturally determined; however, it soon transformed into a list of traits/stereotypes about various cultural groups that learners would memorize, and it led to stereotypical reactions. This generated a paradigm shift towards cultural humility to emphasize ongoing humility, reflection and lifelong learning [20]. However, as the corona virus disease 19 (COVID-19) pandemic has shown, there are additional structures which constantly affect health outcomes. Policies (lack of accessible material for the deaf), economic systems (migrants stuck in inhospitable habitats during the nation-wide lockdown), and social hierarchies (flagrant racism against a particular community or lifestyle) interplay with inequalities and leads to a deepening of health disparities.

An IMG should recognize such structural barriers as patients may not be able to identify them. Structural competency is perhaps a better way of looking at things as it builds upon the sociocultural conditions that produce inequalities in health in the first place [20]. Acknowledging our biases and looking at the underlying structural oppression that contributes to it is perhaps structural humility. Structural humility is looking beyond one's own experience (as well as admitting ignorance) and approaching the experiences of others without judgment and without our own biases. It is a lifelong commitment to the development of self-critique, reflection, and a capacity for empathy at both intrapersonal and interpersonal levels [21]. 
In our experience, empathy decline replaces the initial enthusiasm and humanity that students present with at the beginning of the medical course. When confronted with clinical reality, there is a decline in empathy over the clinical phase of training [22]. Empathy is the hallmark of the provider-patient communication and plays a vital role in achieving patient-centeredness. The empathy decline we are witness to is of serious concern and must be addressed.

What begins from the pre- and para-clinical departments with an emphasis on dissection and vivisection continues into the clinics with a paternalistic approach to decision-making. This leads to a bias towards curative rather than caring medicine. In a country as diverse as India with respect to culture, language and inequities, it is challenging for a medical student to imagine the experiences of a culturally different patient. This is where the cultural competency model fails as it might invoke unintentional tubular vision into cultures. We experienced this in the COVID-19 pandemic, where cultural and culinary practices were wrongly linked with the contagion. This is where identifying the structural oppression and stepping back from being an 'expert' is required. Structural humility seeks to bridge the divide between structural competence and cultural humility.

\section{INCORPORATING HUMANITIES IN HPE}

\section{The Tools}

The connection between the roles of an IMG, the desired $\mathrm{ABCDE}$ attributes, and the humanistic competencies is shown in Table I. It also suggests humanities tools that could help in achieving the humanistic competencies. These tools are equally applicable to virtual environments, for as humanists, we need to pay attention to 'webside' manners also.

\section{The Facilitators}

Any faculty member, resident, or groups of students with a special interest in any of these diverse tools may be encouraged to employ a humanities approach in their teaching-learning activities. An interdisciplinary approach assures that a number of teachers, with diverse skills, are available at any given time. Understandably, depending on local interest and inclinations, different institutions will focus on different tools. In addition, a trans-disciplinary approach may be employed where faculty from the humanities disciplines, and experts from outside academia may be invited to contribute to learning. An eclectic mix of people may be more meaningful in understanding the nuances of interpersonal relationships and real-life communication $[23,24]$.

\section{The Timetable}

The gazette notification of MCI of 6 November, 2019 heralding the CBME mentions humanities as a new teaching element in the preclinical phase of medical education [14]. In addition, cultural competence and disability competencies (after our judicial advocacy) have been made part of the month-long foundation course [12]. The highlight of the CBME undoubtedly is the inclusion of the Attitude, Ethics and Communication (AETCOM) module longitudinally throughout the curriculum. In addition, two optional electives of one month each are scheduled after the end of third MBBS (Part I). Electives are ideal to implement a complete health humanities module. Its optional nature will encourage small groups and critical thinking, although with our large overall class sizes, achieving a realistic small group may not be possible. At our institution, we used the health humanities to introduce the first-year medical students to disability competencies during the foundation course in 2019.

The draft of the revised Nursing Curriculum by the Indian Nursing Council (INC) categorically states that "Nursing as a profession and a discipline utilizes knowledge derived from arts, sciences, humanities and human experience" [15]. Humanities may be applied directly during semester III (professionalism, professional values and ethics including bioethics), IV (nursing education), $\mathrm{V}$ (mental health nursing and Indian laws), and also as an elective in semester III and IV (human values; palliative care), and VII and VIII (soft skills).

Whether we incorporate humanities during the foundation course, phase I, or during electives, it is important not to compartmentalize the experience but to use it in a creative and flexible way [25]. We suggest using humanities as a tool to teach AETCOM and to utilize the self-directed learning hours towards building the five humanistic competencies described above. Informal opportunities may present themselves and should be exploited for initiatives to teach health humanities. We suggest the near-peer mentoring network, student cultural societies, lunch break, and Saturday afternoons to be used in a productive way to hone humanistic competencies [1$3,23,24]$. In addition, together with students, faculty may explore how humanities may be used during early clinical exposure and self-directed learning hours. In fact, every interaction presents an opportunity, and it need not be limited to the classroom, to a field visit, or to a clinic.

\section{Assessment}

Competency based assessment (be it formative or summative) is challenging in the humanities as the latter, by design, is meant to be disruptive. In the classroom, 
limiting student learning by defining specific learning objectives is deemed to be anti-educational in the context of something as versatile as the health humanities. Moreover, many humanistic competencies are not easily amenable to reliable assessment. However, if one is to assess the learning that accrues from the health humanities, then the outcome can be made quite meaningful by assessing multiple times and in different contexts.

Theatre of the oppressed, being a performance-based intervention, already lends itself well to a formative assessment in the form of observations recorded by facilitators (non-jokers) in the games and exercises which form an important component $[10,11]$. In that sense, it answers the call of competency-based assessment and feedback. Its more nuanced form, forum theatre, in terms of Miller pyramid, falls under the topmost 'does' category, where learners, by becoming spect-actors, allow direct observation of the skills displayed during the intervention, which can then generate authentic feedback [26].

Assessment during humanities electives may be directed towards a portfolio comprising a mix of written reflections, essays, narratives, poems, and a humanities research project. For longitudinal programs like AETCOM, Objective Structured Clinical Examination, bedside discussion, Workplace-based assessment, Stan-dardized patients and Multi-source feedback may be used.

\section{Evaluation}

For program evaluation, we suggest a mixed methods approach utilizing both quantitative (standardized surveys, in-house program evaluation instruments) and qualitative methods (semi-structured interviews, focus groups, observation notes). Qualitative methods in particular can be used to explore students' experiences and needs, and processes of the humanities program so that it can be improved and replicated in other institutions. In our study on developing disability competencies, we relied on focus group discussions to give a voice to historically neglected stakeholders (doctors with disabilities) [12]. Focus group discussions are particularly helpful in that they capture laughter and expressions of sadness which might not be gauged by quantitative studies.

\section{Challenges Within the Competency-based Curriculum}

One of the biggest challenges will be where to fit the health humanities in the curriculum. The MCI gazette mentions humanities as a new teaching element in phase-I but it does not schedule teaching hours (Table IV,pg 69 of gazette) which makes it unclear where it will be clubbed [14]. The elective nature of the humanities module in the curriculum may not attract the students who really need an exposure to creativity - like those who are stressed more than usual, who are isolated, are experiencing a decline in empathy, have non-conventional learning styles, or have poor communication skills. Perhaps, teachers could identify students in need and nudge them towards a humanities elective. As passionate humanists we would love to see all HPE students being exposed to humanities. However, this wish list is more of a burden considering the student batch size in HPE courses in India. The mandatory approach might work (if handled with discernment) for a session with less than 100 students, but might be counter-productive for a batch of 250-plus.

The other problem may result from an inadequate or ill-prepared faculty. As mentioned earlier, interested faculty should be recruited; however, they may still need to be oriented to the program and trained in the humanistic competencies. Though it looks like a daunting task initially, we imagine that the effort will snowball as more and more faculty get trained. This effect is already in evidence in the country with every National Conference on Health Professions Education including the humanities in one way or the other in the program schedule. Senior residents could fill the gap; however, they are not entitled to attend MCI-mandated revised basic courses. Senior resident training on education principles (STEP) or similar workshops could be conducted in other institutions [27].

Another problem we foresee is that, though there is an 8-hour module of 'Music and Healing' mentioned in the Curriculum Implementation Support Program (CISP) booklet of the CBME under the humanities section, the instructional modality outlined there as well as in the AETCOM module is largely case studies based - a "problem-solving" model. This model is largely criticized by humanists as a threat to critical thinking [25]. Having an inflexible humanities curriculum, with the same cases presented across the country in a non-contextual way, could jeopardize innovation and creati-vity, and is anathema to the very idea of humanities edu-cation. Assessment of acquisition of humanistic competencies is likely to be another challenge. As teachers, we may not necessarily be able to grade the quality of submissions made by learners in response to humanities initiatives. That they must be evaluated goes without saying in view of the paradigm that assessment drives learning. Fortunately, it is possible to make objective assessments using prepared rubrics like Narrative Reflection Assessment Rubric (NARRA) and Reflection Evaluation for Learners' Enhanced Competencies Tool (REFLECT) $[28,29]$. Some training in the use of these rubrics may be required. 


\section{Future Directions}

The All India Institute of Medical Sciences (AIIMS), Delhi is revising its curriculum to make it competency based. Naturally, the new AIIMS like institutions will adopt the same. This opportunity should not be missed, and areas not addressed in the MCI curriculum should be incorporated in this curriculum. The Dental Council of India should also make similar efforts.

The draft nursing curriculum of INC makes only a superficial pitch to humanities. Its further insistence on soft skills gives the message that these competencies are optional. Unlike MCI, they invited stakeholder feedback early this year and we hope that they will act on them to make it a truly inclusive curriculum.

The pharmacy practice curriculum has not received much attention in India, even though experts stress that "pharmacy is a profession that has at its core a human relationship" [30]. Thus, the regulatory body must consider upgrading the pharmacy curriculum.

\section{CONCLUSION}

The potential for the humanities in health professions education is increasingly being recognized and accepted in the Indian context. Of the many tools available, teachers and learners may choose those that are supported by local interest groups or by expertise in their specific setting. Scheduling the sessions is dependent on local facilities and should not be restricted to traditional settings or the formal curriculum. Assessment is likely to be challenging but can find a place in the newer modalities being rolled out in the new competency-based curriculum. Evaluation of health humanities modules are desirable and educators who are spearheading such movements must share experiences, resources and expertise. The framework we suggest may be used by Councils/Institutions currently modifying their curriculum, and we encourage them to hone and develop it in innovative ways to make it as robust as possible. Flexibility is the key to the health humanities and creativity is its oxygen.

Contributors: All authors conceptualized, wrote, critically reviewed and revised the manuscript, and approved the final version.

Funding: None; Competing interest: None stated.

\section{REFERENCES}

1. Bhatia A, Singh N, Dhaliwal U. Mentoring for first year medical students: Humanising medical education. Indian J Med Ethics. 2013;10:100-3.

2. Dhaliwal U, Singh S, Singh N. Reflective student narratives: Honing professionalism and empathy. Indian J Med Ethics. 2018;3:9-15.
3. Singh S, Singh N, Dhaliwal U. Near-peer mentoring to complement faculty mentoring of first-year medical students in India. J Educ Eval Health Prof. 2014;11:12.

4. Singh S, Singh N, Dhaliwal, U. Promoting competence in undergraduate medical students through the humanities: The ABCDE Paradigm. Research and Humanities in Medical Education. 2015;2:28-36.

5. Singh N. Whither medical humanities? Indian J Med Ethics. 2012;9:166-9.

6. Bates V, Bleakley A, Goodman S, editors. Medicine, Health and the Arts: Approaches to the Medical Humanities. Routledge; 2014.

7. Atkinson S, Evans B, Woods A, Kearns R. 'The medical' and 'health' in a critical medical humanities. J Med Humanit. 2015;36:71-81.

8. Klugman CM. How health humanities will save the life of the humanities. J Med Humanit. 2017;38:419-30.

9. Academy of Health Professions Educators: Special Interest Groups. Available from: https://ahpe.in/special-interestgroups/. Accessed July 03, 2020.

10. Singh S, Kalra J, Das S, Barua P, Singh N, Dhaliwal U. Transformational learning for health professionals through a theatre of the oppressed workshop. Med Humanit. 2019;medhum-2019-011718 [Epub ahead of print].

11. Singh S, Barua P, Dhaliwal U, Singh N. Harnessing the medical humanities for experiential learning. Indian J Med Ethics. 2017;2:147-52.

12. Singh S, Cotts KG, Maroof KA, Dhaliwal U, Singh N, Xie T. Disability-inclusive compassionate care: Disability competencies for an Indian medical graduate. J Family Med Prim Care. 2020;9:1719-27.

13. Peterkin A. Curating the medical humanities curriculum: Twelve tips. Med Humanit. 2016;42:147-8.

14. Medical Council of India. Regulations on Graduate Medical Education, 1997 - Addition as part - II for MBBS course Starting from Academic Year 2019-20 Onwards. e-Gazette 6. Available from: https://mciindia.org/ActivitiWebClient/ open/get-Document?path=/Documents/Public/Portal/ Gazette/GME-06.11.2019.pdf. Accessed April 11, 2020.

15. Indian Nursing Council. Revised basic B.Sc Nursing syllabus. Available from: http://www. indiannursing council.org/pdf/BSCSyllabus_2019-20.pdf. Accessed April 11, 2020.

16. Das Gupta S. Narrative humility. Lancet. 2008;371:980-1.

17. Kinsella EA, Caty M, Ng S, Jenkins K. Reflective practice for allied health: Theory and applications. In: English L, ed. Adult Education and Health. Toronto: University of Toronto Press; 2012. p. 210-28.

18. Meeks LM, Maraki I, Singh S, Curry RH. Global commitments to disability inclusion in health professions. Lancet. 2020;395:852-53.

19. Salian P. One doctor's disability may lead to curriculum change in India. BMJ. 2019;365:14215.

20. Tsevat RK, Sinha AA, Gutierrez KJ, DasGupta S. Bringing home the health humanities: Narrative humility, structural competency, and engaged pedagogy. Acad Med. 2015; 90:1462-5.

21. Hughes V, Delva S, Nkimbeng M, Spaulding E, TurksonOcran RA, Cudjoe J, et al. Not missing the opportunity: 
Strategies to promote cultural humility among future nursing faculty. J Prof Nurs. 2020;36:28-33.

22. Chatterjee A, Ravikumar R, Singh S, Chauhan PS, Goel M. Clinical empathy in medical students in India measured using the Jefferson Scale of Empathy-Student Version. J Educ Eval Health Prof. 2017;14:33.

23. Gupta R, Singh S, Kotru M. Reaching people through medical humanities: An initiative. J Educ Eval Health Prof. 2011;8:5.

24. Gupta S, Singh S. Confluence: Understanding medical humanities through street theatre. Med Humanit. 2011; 37:127-8.

25. Prabhu G. The disappearing act: Humanities in the medical curriculum in India. Indian J Med Ethics. 2019;4:194-7.

26. Gupta S, Agrawal A, Singh S, Singh N. Theatre of the oppressed in medical humanities education: The road less travelled. Indian J Med Ethics. 2013;10:200-3.

27. Singh S. Senior Resident Training on Educational Principles (STEP): A Proposed Innovative Step from a Developing Nation. J Educ Eval Health Prof. 2010;7:3.

28. Alsina A, Ayllón S, Colomer J. Validating the Narrative Reflection Assessment Rubric (NARRA) for reflective narratives in higher education. Assess Eval High Educ. 2019;44:155-68.

29. Wald HS, Borkan JM, Taylor JS, Anthony D, Reis SP. Fostering and evaluating reflective capacity in medical education: Developing the REFLECT rubric for assessing reflective writing. Acad Med. 2012;87:41-50.

30. Poirier TI, Stamper-Carr C. A call for a new ism in pharmacy. Am J Pharm Educ. 2018;82:6441. 